\title{
META-ANALYSIS: MENGEVALUASI EFEKTIVITAS PROBLEM- BASED LEARNING PADA KEMAMPUAN PEMAHAMAN MATEMATIS SISWA
}

\author{
Yulina Kartika Sari ${ }^{1}$, Dadang Juandi ${ }^{1}$, Maximus Tamur ${ }^{2}$, Angela M G Adem ${ }^{3}$ \\ Universitas Pendidikan Indonesia, Jl. Dr. Sutomo No. 100, Bandung, Indonesial \\ Universitas Katolik Indonesia Santu Paulus Ruteng, Jl. Jend. A. Yani No. 10, Ruteng, Indonesia ${ }^{2}$ \\ Teachers College of Columbia University, 525 W 120th St, New York, NY 10027, United States ${ }^{3}$ \\ E-mail: maximustamur@unikastpaulus.ac.id
}

\begin{abstract}
Abstrak
Problem based learning (PBL) telah diterapkan secara luas sebagai metode pembelajaran dalam pendidikan matematika. Studi meta-analisis ini dilakukan untuk merangkum bukti tentang efektivitas PBL pada kemampuan pemahaman siswa. Database terkait dicari untuk studi yang memenuhi kriteria inklusi. Metode estimasi menggunakan model efek-acak dengan interval kepercayaan 95\% (CI). Penelitian ini menganalisis 35 ukuran efek dari 22 studi primer yang telah diterbitkan antara tahun tahun 2011 hingga 2020, dan dengan total 1993 siswa dilibatkan. Program Comprehensive Meta-Analysis (CMA) digunakan untuk membantu analisis. Sebagai hasil dari penelitian, ukuran efek keseluruhan adalah 0,790 (efek sedang) dengan simpangan baku 0,181. Analisis karakteristik studi mengungkapkan bahwa penerapan PBL lebih efektif pada kondisi ukuran sampel yang diatur 1-30 siswa, jenjang pendidikan yang lebih rendah, dan dikombinasikan dengan penggunaan software pembelajaran matematika. Temuan ini menjadi pertimbangan praktisi pendidikan matematika untuk ilmplementasi PBL di masa depan.
\end{abstract}

Kata Kunci: Meta-Analisis, Problem Based Learning, Kemampuan Pemahaman Matematis, Karakteristik Studi

\begin{abstract}
Problem-based learning (PBL) has been widely applied as a learning method in mathematics education. This meta-analysis study was conducted to summarize the evidence on the effectiveness of PBL on students' comprehension abilities. An associated database was searched for studies that met the inclusion criteria. The estimation method used a random-effect model with a $95 \%$ confidence interval (CI). The study analyzed 35 effect sizes from 22 primary studies published between 2011 and 2020, and for a total of 1993, students were included. The Comprehensive Meta-Analysis (CMA) program was used to assist the analysis. As a result of the study, the overall effect size was 0.790 (moderate effect) with a standard error of 0.181 . Analysis of the study characteristics revealed that the application of PBL was more effective in the conditions of the sample size set by 1 - 30 students, lower level of education, and combined with the use of mathematics learning software. These findings become a consideration for mathematics education practitioners for the implementation of PBL in the future.
\end{abstract}

Keywords: Meta-Analysis, Problem Based Learning, Mathematical Understanding Ability, Study Characteristics

\section{PENDAHULUAN}

Tujuan siswa belajar matematika adalah untuk mengembangkan dan memperdalam 
pemahaman konsep matematis (Kusmaryono, 2014; Minarni et al., 2016; NCTM, 2000) yang merupakan bagian penting dalam proses pembelajaran matematika (Lambertus, 2016). Pemahaman matematis penting untuk ditanamkan kepada siswa untuk dapat menyelesaikan permasalahan dengan lebih baik (Dewimarni, 2017; Marlena \& Nugraheni, 2019; Prahmana, 2013). Jelas bahwa kemampuan pemahaman matematis berkontribusi pada kesuksesan siswa.

Kemampuan pemahaman matematika dapat dikembangkan dengan penggunaan model pembelajaran yang tepat (Freeman-Green et al., 2015). Sementara, proses pembelajaran yang melibatkan pemecahan masalah dapat mengembangkan kemampuan pemahaman matematis siswa (Minarni et al., 2016). Dengan demikian kemampuan pemahaman matematis diantaranya dapat ditingkatkan melalui pembelajaran berbasis masalah.

Selama bertahun-tahun, tampaknya ada peningkatan dalam penerapan Pembelajaran Berbasis Masalah (Problem based learning / PBL) dalam pendidikan (Ceker \& Ozdamli, 2016). Implementasi PBL yang semakin populer dalam pendidikan matematika telah memicu kesibukan penelitian yang berfokus pada efektivitasnya terhadap kemampuan pemahaman matematis dalam pendidikan dasar dan menengah. Berbagai penelitian tersebut memastikan keefektifan PBL menggunakan desain eksperimental atau kuasieksperimental (misalnya: Afridiani et al., 2020; Alan \& Afriansyah, 2017; Aripin, 2015; Dalim et al., 2019; Munawaroh \& Deniyanti Sampoerno, 2018; Muhsin \& Taufiq, 2019; Siregar et al., 2011; Rahmadani \& Acesta, 2017; Warniasih, 2018). Namun penelitian lainnya menemukan bahwa PBL tidak lebih baik dari pembelajaran konvensional (misalnya; Hidayat \& Nurrohmah, 2016; Sari et al., 2019; Supriatna \& Afriansyah, 2017; Wardhani et al., 2016).

Sampai saat ini belum ada studi tunggal yang dapat secara meyakinkan menunjukkan efektivitas PBL secara konsisten pada kemampuan pemahaman matematis siswa. Variabel kategori studi dari efektivitas PBL yang teridentifikasi memperlihatkan adanya heterogeneitas studi (Demirel \& Dağyar, 2016; Gijbels et al., 2005; Qin et al., 2016). Dilain pihak, efektivitas PBL dimoderasi oleh variable kategori yang menyertainya (Hasibuan et al., 2019; Jacinto \& Carreira, 2017; Ke \& Clark, 2020; Susanti, Juandi, \& Tamur, 2020; Paloloang et al., 2020; Suparman. Juandi, \& Tamur, 2021; Yunita et al., 2020). Belum ada studi primer yang menyelidiki variasi hasil dari 
pengaruh PBL terhadap kemampuan matematis siswa. Disisi lain, praktisi pendidikan membutuhkan kesimpulan yang meyakinkan bahwa dibawah kondisi yang seperti apa PBL efektif dalam meningkatkan kemampuan pemahaman matematis siswa.

Tinjauan literatur dari berbagai studi memungkinkan terjadinya variasi hasil (Franzen, 2020) bahkan bertentangan antara yang satu dengan yang lainnya (Tamur, Jehadus, Nendi, Mandur, \& Murni, 2020; Tamur, Juandi, \& Kusumah, 2020). Di sisi lain, tinjauan literatur harus memberikan kesimpulan yang meyakinkan (Juandi et al., 2021; Siddaway et al., 2019). Penggunaan temuan kuantitatif yang meyakinkan ini memberikan informasi yang berguna untuk penetapan kebijakan (Higgins \& Katsipataki, 2015). Dengan demikian, ketika ada kebutuhan untuk menarik kesimpulan umum, perlu untuk memperhitungkan hasil dari berbagai studi individu menggunakan metode meta-analisis (Tamur \& Juandi, 2020).

Meta-analisis diimplementasikan untuk meringkas temuan dan menganalisis sejauhmana karakteristik studi primer memoderasi hubungan PBL dengan kemampuan pemahaman matematis. Temuan ini akan berkontribusi bagi implementasi PBL yang ideal dimasa depan. Meta-analisis dipandang sebagai cara populer untuk menggabungkan hasil dari beberapa studi primer, membandingkan beberapa perlakuan (White, 2015), meringkas dan menjelaskannya secara lebih luas (Green, 2005; Stanley et al., 2013). Prosedur meta-analisis mengabaikan penafsiran subjektif terhadap tinjauan penelitian yang bervariasi pada topik yang sama (Borenstein \& Hedges, 2009). Lebih lanjut, metaanalisis memberikan bukti kumulatif dengan mengurangi efek distorsi dari studi primer sehingga mengurangi konflik dari temuan yang berbeda, dan membantu untuk menciptakan pemahaman serta mengembangkan teori dengan mengidentifikasi hubungan antar karakteristik studi (Schmidt \& Hunter, 2015).

Dalam literatur, laporan meta-analisis sebelumnya memberikan tinjauan yang umum tentang efek penerapan PBL dibandingkan dengan metode konvensional (Demirel \& Dağyar, 2016; Dochy et al., 2003; Gijbels et al., 2005; Rosli et al., 2014; Wang et al., 2016). Studi-studi tersebut, belum secara khusus meneliti tentang efek PBL pada kemampuan pemahaman matematis siswa. Sementara itu studi meta-analisis yang telah dilakukan di Indonesia tentang efek penerapan PBL (misalnya; Anugraheni, 2018; Yanto et al., 2019) belum melibatkan analisis statistik yang merupakan esensi dari studi metaanalisis. Hanya Asror (2016) yang telah melakukan meta-analisis dan melibatkan analisis 
statistik. Akan tetapi penelitian tersebut tidak dilakukan analisis bias publikasi, dan model estimasi yang seharusnya dipilih tidak dijelaskan. Akibatnya ukuran efek yang diperoleh direpresentasikan secara berlebihan.

Penelitian ini melengkapi penelitian sebelumnya yang mempertanyakan efek PBL pada kemampuan pemahaman matematis siswa. Pekerjaan meta-analisis adalah menganalisis berbagai studi primer pada topik yang sama memungkinkan adanya variasi dalam ukuran efek (Tamur, Juandi, \& Adem, 2020; (Tamur, Jehadus, Negara, Siagian, Marzuki, \& Sulastri, 2021). Tujuan penelitian ini adalah menentukan besarnya efek PBL pada kemampuan pemahaman matematis siswa, dan meneliti sejauhmana karakteristik studi memoderasi efektifitas PBL. Penjelasan tersebut menunjukkan pentingnya melakukan meta-analisis secara komprehensif tentang efektivitas PBL terhadap kemampuan pemahaman matematis siswa di Indonesia sejak tahun 2011 sampai 2020. Hal ini diperlukan untuk mengevaluasi penggunaannya dan melihat tren keseluruhan secara lebih jelas.

\section{METODE}

\section{Desain Penelitian}

Penelitian ini menggunakan meta-analisis yaitu menggabungkan dua atau lebih studi primer yang telah diterbitkan untuk mengintegrasikan temuan (Schmidt \& Hunter, 2015; Glass, 2015). Penelitian ini telah menganalisis studi primer yang mempertanyakan efek PBL pada kemampuan pemahaman matematis siswa. Seperti tahapan meta-analisis umumnya yang telah diterapkan oleh Borenstein et al. (2009) dan Pigott (2012) penelitian ini juga mengikuti tahapan serupa yaitu menentukan kriteria inklusi, melakukan pengumpulan data dan pengkodean variabel, dan analisis statistik.

\section{Kriteria Inklusi}

Ada beberapa kriteria inklusi yaitu kelayakan standar yang digunakan dalam menyaring data empiris yaitu; (a) dalam bentuk Journal, Prosiding, Tesis dan disertasi; (b) adalah hasil penelitian di Indonesia tentang efek PBL pada kemampuan pemahaman matematis siswa; (c) publikasi setidaknya dalam satu dekade terakhir (2010-2020); dan (e) publikasi memiliki informasi statistik untuk transformasi ukuran efek yaitu; rata-rata, simpangan baku dan ukuran sampel. 


\section{Pengumpulan Data}

Penelitian meta-analisis dicirikan oleh pencarian literatur yang menyeluruh. Definisi yang jelas dari hipotesis yang akan diuji memberikan kerangka kerja untuk pencarian tersebut. Penting untuk mendapatkan semua studi yang relevan, karena kehilangan studi dapat menyebabkan bias dalam penelitian ini. Data empiris diperoleh dari artikel yang diterbitkan dan abstrak diidentifikasi oleh pencarian literatur komputer dari database elektronik yang mencakup ERIC (https://eric.ed.gov/?journals), SAGE Publishing (https://us.sagepub.com/en-us/nam/journals) dan Google Scholar (https://scholar.google.co.id/schhp?hl=id). Pencarian basis data juga diperoleh dengan pencarian manual sumber perpustakaan untuk tesis dan disertasi di Universitas Pendidikan Indonesia. Pemeriksaan referensi silang telah dilakukan melalui komunikasi email dengan para peneliti studi primer. Tahapan ini menemukan 82 studi tentang pengaruh PBL terhadap kemampuan matematis siswa. Berdasarkan kriteria inklusi, 22 studi primer yang memenuhi kelayakan untuk dianalisis. Rincian studi primer berdasarkan lokasi pencarian adalah 19 dari pencarian berbasis data elektronik, dan 3 dari pencarian manual. Beberapa studi yang membandingkan lebih dari satu kelompok pembanding sehingga banyaknya ukuran efek yang dianalisis adalah 35 .

\section{Pengkodean Data}

Instrumen yang digunakan dalam penelitian ini adalah lembaran pengkodean variabel. Proses pengkodean selain membantu peneliti dalam menganalisis data, juga menghindari data yang terlupakan. Pengkodean dalam analisis data meliputi informasi yang diekstrak dari studi primer yaitu tahun penelitian, ukuran sampel, kombinasi model yang digunakan, dan jenjang pendidikan. Guna memastikan data yang dimasukan tanpa salah, dua pengkode mengisi formulir pengkodean secara terpisah dan kemudian dibandingkan. Jika masih ada data yang belum sama, maka dilakukan diverifikasi ulang.

\section{Analisis Statistik}

Data dianalisis secara statistik dengan mengikuti mengikuti tahapan Borenstein \& Hedges (2009) yaitu; (a) menentukan ukuran efek setiap studi; (b) menentukan tes heterogenitas ukuran efek; (c) menentukan bias publikasi; dan (d) menghitung nilai-p. Untuk menilai sejauhmana karakteristik studi memoderasi PBL, dilakukan setelah 
diketahui model yang diestimasi adalah model efek-acak. Aplikasi yang membantu analisis data adalah pprogram Compherensive Meta-Analysis (CMA). Persamaan Hedge's $\mathrm{g}$ digunakan untuk menentukan indeks ukuran efek. Interpretasi ukuran efek, menggunakan klasifikasi Cohen et al. (2007) seperti yang terlihat pada Tabel 1.

Tabel 1. Interpretasi Ukuran Efek

\begin{tabular}{cc}
\hline Rentangan Effect Size (ES) & Interpretasi \\
\hline $\mathrm{ES} \leq 0,20$ & Efek lemah \\
$0,20<\mathrm{ES} \leq 0,50$ & Efek sederhana \\
$0,50<\mathrm{ES} \leq 1,00$ & Efek sedang \\
$\mathrm{ES}>1,00$ & Efek kuat \\
\hline
\end{tabular}

CMA dapat menghitung nilai $\mathrm{Z}$ yang digunakan untuk uji signifikansi pengaruh PBL pada kemampuan matematis siswa, dan memberikan ukuran efek rata-rata dengan interval kepercayaan untuk setiap kelas variabel serta homogenitas antar kelompok yaitu nilai Qb. Jika $Z_{\text {hitung }}>Z_{\text {table }}$ dengan $\mathrm{p}<0,05$ maka hipotesis nol ditolak (Borenstein et al., 2009). Hal ini mengindikasikan bahwa penerapan PBL menghasilkan ukuran efek yang positif terhadap kemampuan matematis siswa dibandingkan pendekatan konvensional. Selanjutnya, keputusan terpenting yang harus dibuat ketika melakukan meta-analisis adalah apakah akan menggunakan model estimasi efek-tetap atau efek-acak (Haidich, 2010). Model efek-tetap menandakan bahwa ukuran efek antar studi atau kelompok studi homogen. Model efek-acak digunakan ketika ukuran efek secara statistik heterogen $(\mathrm{Qb}>\chi 2.95 ; \mathrm{p}<0,05)$. Menolak $\mathrm{Qb}$ menyiratkan bahwa ukuran efek antar studi atau kelompok studi mungkin tidak mengukur parameter populasi yang sama (Borenstein et al., 2009). Dengan perkataan lain, ada perbedaan yang signifikan secara statistik dalam ukuran efek gabungan untuk setiap kelompok karateristik studi (Khan, 2020).

\section{HASIL PENELITIAN DAN PEMBAHASAN}

Tujuan utama dari studi meta-analisis ini adalah menemukan ukuran efek gabungan pembelajaran yang menerapkan PBL terhadap kemampuan pemahaman matematis siswa. Ringkasan hasil perhitungan disajikan pada Tabel 2, yang menunjukkan bahwa ukuran efek tiap studi beragam. Terdapat 4 ukuran efek yang bernilai negatif menunjukan keunggulan kelompok kontrol yang memperoleh pembelajaran konvensional dari pada kelompok eksperimen yang memperoleh pembelajaran PBL. Selain itu, terdapat 31 ukuran efek positif yang menjelaskan keunggulan kelompok eksperimen. Hal ini 
memperlihatkan adanya variasi hasil dalam penerapan PBL pada kemampuan pemahaman matematis siswa.

Table 2. Ukuran Efek Tiap Studi

\begin{tabular}{|c|c|c|c|c|}
\hline \multirow{2}{*}{ Penulis Studi Primer } & \multirow{2}{*}{$\begin{array}{c}\text { Ukuran } \\
\text { Efek }\end{array}$} & \multirow{2}{*}{$\begin{array}{c}\text { Simpangan } \\
\text { Baku }\end{array}$} & \multicolumn{2}{|c|}{ Selang Kepercayaan } \\
\hline & & & Batas Bawah & Batas Atas \\
\hline Afridiani et al, 2018 & 0,45 & 0,24 & $-0,02$ & 0,92 \\
\hline Alan \& Afriansyah, 2017 & $-0,64$ & 0,25 & $-1,13$ & $-0,15$ \\
\hline Anwar, 2020a & 1,58 & 0,72 & 0,16 & 3,00 \\
\hline Anwar, 2020b & 0,47 & 0,45 & $-0,42$ & 1,36 \\
\hline Anwar, 2020c & 0,33 & 0,32 & $-0,29$ & 0,96 \\
\hline Aripin, 2015 & 0,75 & 0,28 & 0,2 & 1,31 \\
\hline Asih, Sutiarso, \& Wijaya, 2018a & $-0,04$ & 0,26 & $-0,55$ & 0,47 \\
\hline Asih, Sutiarso, \& Wijaya, 2018b & 1,45 & 0,29 & 0,87 & 2,02 \\
\hline Asih, Sutiarso, \& Wijaya, 2018c & 1,29 & 0,29 & 0,73 & 1,86 \\
\hline Asnila et al, 2016 & 0,61 & 0,31 & 0,02 & 1,21 \\
\hline Batubara, 2017 & 0,88 & 0,27 & 0,35 & 1,40 \\
\hline Dalim, Rosita, \& Dewi, 2019 & 0,87 & 0,27 & 0,34 & 1,40 \\
\hline Ejin, 2015a & 2,55 & 0,43 & 1,71 & 3,38 \\
\hline Ejin, $2015 b$ & 1,39 & 0,35 & 0,7 & 2,08 \\
\hline Hidayat \& Nurrohmah, 2014a & 2,29 & 0,74 & 0,84 & 3,75 \\
\hline Hidayat \& Nurrohmah, 2014b & 1,10 & 0,31 & 0,49 & 1,7 \\
\hline Hidayat \& Nurrohmah, 2014c & 1,12 & 0,82 & $-0,49$ & 2,72 \\
\hline Hidayat \& Nurrohmah, 2014d & 1,33 & 0,27 & 0,8 & 1,85 \\
\hline Minarni, 2013a & 0,71 & 0,17 & 0,38 & 1,05 \\
\hline Minarni, 2013b & 0,32 & 0,17 & $-0,01$ & 0,65 \\
\hline Mudhiah \& Shodikin, 2019a & 1,82 & 0,36 & 1,12 & 2,52 \\
\hline Mudhiah \& Shodikin, 2019b & 0,56 & 0,31 & $-0,04$ & 1,17 \\
\hline Nurcahya et al, 2020 & 0,77 & 0,27 & 0,24 & 1,29 \\
\hline Nurdini, $2017 \mathrm{a}$ & 0,42 & 0,25 & $-0,07$ & 0,9 \\
\hline Nurdini, 2017b & $-0,24$ & 0,25 & $-0,72$ & 0,24 \\
\hline Rahmadani dan Acesta, 2017a & 0,31 & 0,28 & $-0,24$ & 0,85 \\
\hline Rahmadani dan Acesta, 2017b & 1,77 & 0,33 & 1,13 & 2,41 \\
\hline Sari et al,, 2019 & $-0,50$ & 0,25 & $-0,99$ & $-0,01$ \\
\hline Sayekti, 2019 & 0,78 & 0,28 & 0,24 & 1,33 \\
\hline Siregar, 2011a & 0,81 & 0,25 & 0,33 & 1,29 \\
\hline Siregar, 2011b & 1,10 & 0,25 & 0,6 & 1,6 \\
\hline Supriatna \& Afriansyah, 20181a & 0,00 & 0,25 & $-0,49$ & 0,49 \\
\hline Supriatna \& Afriansyah, 20181b & 0,21 & 0,25 & $-0,28$ & 0,7 \\
\hline Tristanti, 2017 & 0,65 & 0,37 & $-0,08$ & 1,39 \\
\hline Utomo, Wahyuni, \& Hariyadi & 1,71 & 0,27 & 1,18 & 2,24 \\
\hline
\end{tabular}

Selanjutnya dilakukan uji heterogenitas ukuran efek antar studi menggunakan statistik Q. Tabel 3 menyajikan perbandingan model estimasi.

Table 3. Perbandingan Hasil Meta-Analisis Sesuai Estimasi

\begin{tabular}{llccc}
\hline \multicolumn{1}{c}{ Model Estimasi } & n & $\mathbf{Q b}_{\mathbf{b}}$ & df $(\mathbf{Q})$ & Nilai-p \\
\hline Model Efek-Tetap & 35 & 439,319 & 34 & 0,000 \\
Model Efek-Acak & 35 & & & \\
\hline
\end{tabular}


Berdasarkan Tabel 3, diperoleh nilai Qb sebesar 439,319. Nilai ini ditemukan lebih besar dari 46,6023 dalam derajat kebebasan 34 pada tabel $\chi 2$. Hasil ini menunjukkan bahwa penyebaran ukuran efek heterogen. Oleh karena itu penelitian ini menggunakan model efek-acak sebagai metode estimasi.

Langkah selanjutnya yaitu menganalisis bias publikasi berdasarkan model efekacak yaitu memeriksa apakah ada kecendrungan jurnal mempublikasikan studi yang signifikan saja sehingga mengarah ke meta-analisis yang tidak menggambarkan populasi (Borenstein et al., 2009). Bias publikasi dapat ditentukan dengan memeriksa plot corong. Tidak ada bias jika distribusi ukuran efek penelitian simetris di antara garis vertikal (Borenstein et al., 2009). Jika tidak sepenuhnya simetris maka statistik gagal-aman N (FSN) Rosenthal diterapkan (Turgut \& Turgut, 2018). Hasilnya tahan terhadap bias publikasi jika nilai FSN / $(5 \mathrm{k}+10)>1$ dimana (k menunjukkan jumlah studi) (Mullen et al., 2001). Gambar 1 memperlihatkan plot corong peneltian.

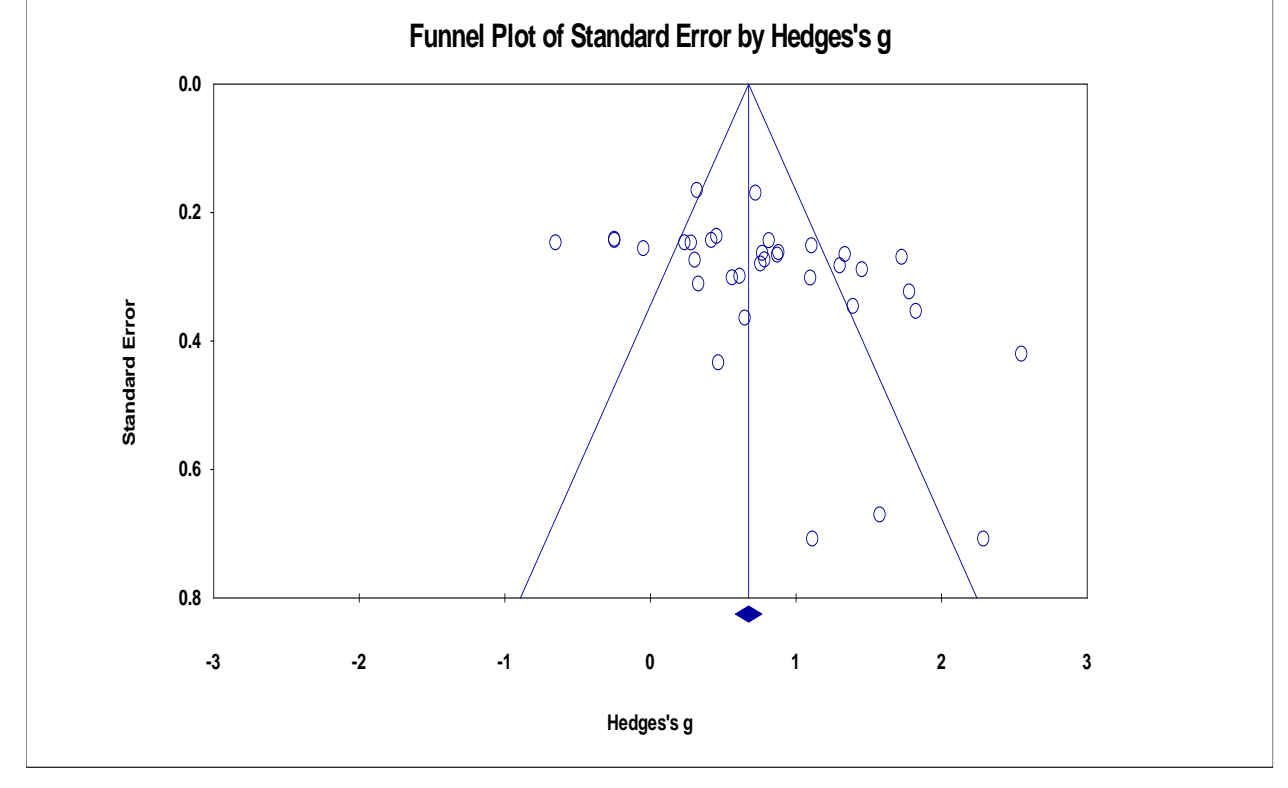

Gambar 1. Plot Corong Penelitian

Gambar 1 menunjukkan bahwa ukuran efek tidak sepenuhnya simetris disekitar garis vertikal. Oleh karena itu statistik gagal-aman N (FSN) Rosenthal diperiksa. Tabel 4 memperlihatkan uji FSN, yang mana nilai N (FSN) dihitung sebagai 2152. Berdasarkan rumus, didapat $2152 /(5 * 35+10)$ yaitu $11,6324>1$. Menurut perhitungan ini maka penelitian ini tahan terhadap bias publikasi. Ini menyiratkan bahwa tidak ada studi yang hilang atau perlu ditambahkan dalam analisis karena bias tersebut. 
Table 4. Statistik gagal-aman N (FSN) Rosenthal

\begin{tabular}{ll}
\hline Kondisi Bias & \\
\hline Nilai Z untuk studi yang diamati & 15,49028 \\
Nilai P untuk studi yang diamati & 0,00000 \\
Alpha & 0,05 \\
Tails & 2 \\
Nilai Z untuk Alpha & 1,95996 \\
Jumlah Studi Teramati & 35 \\
FSN & 2152 \\
\hline
\end{tabular}

Tahap selanjutnya adalah menghitung nilai-p untuk melakukan pengujian terhadap hipotesis penelitian. Tahapan ini dilakukan untuk menentukan efek PBL secara keseluruhan berdasarkan model efek-acak. Tabel 5 memperlihatkan hasil analisis secara keseluruhan, yang mana diperoleh ukuran efek keseluruhan yaitu 0,790 yang diterima sebagai efek sedang menurut klasifikasi Cohen et al. (2007). Lebih lanjut, skor z sebesar 6,040 menunjukkan bahwa hasil penelitian ini signifikan pada tingkat $p<0,001$. Dengan kata lain, secara statistik kedua variabel yang diuji saling berbeda. Jadi, penerapan PBL menghasilkan ukuran efek kemampuan pemahaman matematis siswa yang lebih baik dibandingkan kemampuan pemahaman matematis siswa pada waktu penerapan pendekatan konvensional.

Tabel 5. Hasil Analisis Keseluruhan Berdasarkan Model Efek-Acak

\begin{tabular}{cccccccc}
\hline \multirow{2}{*}{ Model } & \multirow{2}{*}{$\mathrm{n}$} & $\mathrm{z}$ & $\mathrm{p}$ & $\begin{array}{c}\text { Ukuran } \\
\text { Efek }\end{array}$ & $\begin{array}{c}\text { Simpangan } \\
\text { Baku }\end{array}$ & \multicolumn{2}{c}{ Selang Kepercayaan $95 \%$} \\
\cline { 7 - 8 } Efek-Acak & 35 & 6,040 & 0,000 & 0,790 & 0,181 & 0,693 & 0,886 \\
\hline
\end{tabular}

Selanjutnya, telah ditentukan bahwa model efek-acak adalah model estimasi yang dipilih. Akibatnya variasi dalam ukuran efek dievaluasi dari karakteristik studi yang teridentifikasi yaitu; tahun studi, ukuran sampel, jenjang pendidikan, sumber publikasi, dan kombinasi model pembelajaran yang digunakan. Tabel 6 merupakan ringkasan hasil analisis.

Hasil penelitian menunjukkan bahwa ukuran efek keseluruhan studi adalah 0,790 yang mencerminkan bahwa penerapkan PBL memiliki efek sedang terhadap kemampuan pemahaman matematis siswa. Ini menunjukkan bahwa rata-rata siswa yang terpapar PBL melebihi kemampuan pemahman matematis sebesar 76\% siswa di kelas konvesional yang awalnya setara. Dengan perkataan lain, siswa bergeser dari persentil ke-50 ke persentil ke-76 ketika PBL diterapkan. Dilihat dari interpretasi Coe (2002), maka rata-rata siswa 
yang menduduki peringkat ke-14 dalam kelompok eksperimen, setara dengan mereka yang berada di peringkat ke-6 dalam kelompok kontrol.

Tabel 6. Ringkasan Hasil Analisis Berdasarkan Karakteristik Studi Primer

\begin{tabular}{|c|c|c|c|c|c|c|c|c|}
\hline \multirow{2}{*}{$\begin{array}{l}\text { Karakteristik } \\
\text { Studi }\end{array}$} & \multirow{2}{*}{$\begin{array}{l}\text { Kelompok } \\
\text { Studi }\end{array}$} & \multirow{2}{*}{$\mathrm{n}$} & \multirow{2}{*}{ Hedge's g } & \multicolumn{2}{|c|}{$\begin{array}{l}\text { Test of null } \\
\text { (2-Tail) }\end{array}$} & \multicolumn{3}{|c|}{ Heterogeneity } \\
\hline & & & & Z & $\mathrm{p}$ & $\left(Q_{b}\right)$ & $\mathrm{df}(\mathrm{Q})$ & $\mathrm{P}$ \\
\hline \multirow{10}{*}{$\begin{array}{l}\text { Tahun } \\
\text { Penelitian }\end{array}$} & 2011 & 2 & 0,970 & 5,462 & 0,000 & \multirow{10}{*}{80,752} & \multirow{10}{*}{9} & \multirow{10}{*}{0,000} \\
\hline & 2012 & 1 & 1,749 & 6,399 & 0,000 & & & \\
\hline & 2013 & 2 & 1,560 & 9,800 & 0,000 & & & \\
\hline & 2014 & 4 & 1,359 & 7,039 & 0,000 & & & \\
\hline & 2015 & 3 & 1,360 & 6,894 & 0,000 & & & \\
\hline & 2016 & 1 & 0,628 & 2,057 & 0,000 & & & \\
\hline & 2017 & 7 & 0,332 & 3,185 & 0,000 & & & \\
\hline & 2018 & 6 & 0,570 & 5,098 & 0,000 & & & \\
\hline & 2019 & 5 & 0,571 & 0,448 & 0,000 & & & \\
\hline & 2020 & 4 & 0,651 & 3,591 & 0,000 & & & \\
\hline \multirow{3}{*}{$\begin{array}{l}\text { Ukuran } \\
\text { Sampel }\end{array}$} & $1-30$ siswa & 22 & 0,976 & 13,752 & 0,000 & \multirow[b]{2}{*}{13,335} & \multirow[b]{2}{*}{1} & \multirow[b]{2}{*}{0,000} \\
\hline & $\begin{array}{c}31 \text { siswa atau } \\
\text { lebih }\end{array}$ & 13 & 0,615 & 8,966 & 0,000 & & & \\
\hline & $\begin{array}{l}\text { Sekolah Dasar } \\
\text { Sekolah }\end{array}$ & 5 & 1,156 & 8,123 & 0,000 & \multirow{3}{*}{7,726} & \multirow{3}{*}{2} & \multirow{3}{*}{0,021} \\
\hline \multirow[t]{2}{*}{$\begin{array}{l}\text { Jenjang } \\
\text { Pendidikan }\end{array}$} & $\begin{array}{l}\text { Menengah } \\
\text { Pertama }\end{array}$ & 24 & 0,748 & 4,742 & 0,000 & & & \\
\hline & $\begin{array}{c}\text { Sekolah } \\
\text { Menengah Atas }\end{array}$ & 6 & 0,682 & 13,245 & 0,000 & & & \\
\hline \multirow{2}{*}{$\begin{array}{l}\text { Kombinasi } \\
\text { Model } \\
\text { pembelajaran } \\
\text { yang } \\
\text { digunakan }\end{array}$} & $\begin{array}{l}\text { Hanya PBL } \\
\text { PBL dan }\end{array}$ & 30 & 0,744 & 14,312 & 0,000 & \multirow[b]{2}{*}{7,622} & \multirow[b]{2}{*}{1} & \multirow[b]{2}{*}{0,006} \\
\hline & $\begin{array}{c}\text { Software } \\
\text { Pembelajaran } \\
\text { Matematika } \\
\end{array}$ & 5 & 1,199 & 0,218 & 0,000 & & & \\
\hline
\end{tabular}

Hasil ini konsisten dengan hasil studi meta-analisis sebelumnya seperti yang dilakukan oleh Gijbels et al (2005), Rosli et al (2014), dan Wang et al (2016) dengan ukuran efek gabungan masing-masing sebesar 0,$748 ; 0,76$; dan 0,76 . Para peneliti melakukan meta-analisis untuk memeriksa efektivitas PBL terhadap prestasi akademik siswa. Walapun mereka tidak secara khusus melakukan penelitian meta-analisis pada kemampuan pemahaman matematis siswa, temuan ini menunjukan tren keseluruhan yang hampir mirip. Akan tetapi meta-analisis lainnya memperlihatkan hasil yang sedikit berbeda seperti yang dilaporkan oleh Demirel \& Dağyar (2016), dan Dochy et al (2003) dimana masing-masing ukuran efek gabungan 0,44 dan 0,688. Walapun perbedaan hasil ini tergolong kecil namun perlu diteliti lebih lanjut dengan melibatkan lebih banyak studi yang dianalisis untuk memeriksa konsistensinya.

Meta-alisis ini juga menilai perbedaan ukuran efek gabungan dilihat dari 
karateristik studi. Berdasarkan Tabel 6, tampak bahwa nilai skor Z untuk semua karateristik studi ditemukan lebih besar dari $Z_{\text {tabel }}$ pada tingkat $p<0,001$. Hal ini menandakan bahwa penerapan PBL lebih efektif dari pembelajaran konvensional dilihat dari semua karateristik studi. Nilai statistik Qb yang diperoleh sebagai hasil dari uji homogenitas adalah 80,752 lebih besar dari nilai 16,918 pada tingkat kepercayaan $95 \%$, tingkat signifikansi 0,05 dan derajat kebebasan 9. Artinya, terdapat perbedaan yang signifikan dalam ukuran efek antara kelompok menurut tahun penelitian. Ukuran efek gabungan dari kelompok studi yang dilakukan pada tahun 2011 sampai tahun 2020 cenderung menurun. Artinya ada bukti bahwa ukuran efek dari kelompok studi yang lebih lama, lebih baik dari kelompok studi yang terbaru. Temuan ini mengejutkan sebab bertentangan dengan asumsi awal bahwa studi yang lebih baru memuat ukuran efek yang lebih baik. Hal ini mungkin bisa dijelaskan oleh "efek kebaruan" yaitu siswa akan merasa senang dengan metode baru tetapi akan jenuh seiring berjalannya waktu. Temuan serupa juga dilaporkan oleh Suparman et al. (2021) dan Tamur, Juandi, \& Adem (2020) yang masing-masing melakukan meta-analisis tentang trend PBL, dan efektivitas pembelajaran matematika realistik. Artinya, ada kecendrungan bahwa siswa jenuh dengan penggunaan metode yang sama. Karena itu perlu melakukan studi meta-analisis untuk menyelidiki pengaruh durasi perlakuan terhadap efektifitas PBL pada kemampuan pemahaman matematis.

Meta-analisis ini juga menemukan hubungan yang kuat antara efektivitas PBL pada kemampuan matematis siswa dengan ukuran sampel. Berdasarkan Tabel 6, nilai statistik Qb yang diperoleh sebagai hasil dari uji homogenitas adalah 13,335 lebih besar dari nilai 3,841 pada selang kepercayaan 95\%, atau tingkat signifikansi 0,05 dan derajat kebebasan 1. Artinya, terdapat perbedaan yang berarti dalam ukuran efek antara kelompok studi menurut ukuran sampel. Ditemukan bahwa ukuran efek untuk ukuran sampel yang diatur 1 - 30 siswa sebesar 0,976 lebih besar dari ukuran sampel yang diatur 31 siswa atau lebih yaitu 0,615. Hal ini menandakan bahwa model PBL lebih efektif pada kondisi ukuran sampel diatur 1 - 30 siswa. Temuan ini didukung oleh meta-analisis sebelumnya walaupun model yang digunakan berbeda (Tamur, Juandi, \& Adem, 2020).

Dilihat dari jenjang pendidikan, ringkasan hasil pada Tabel 7 menunjukkan nilai statistik Qb yang diperoleh sebagai hasil dari uji homogenitas adalah 7,726 lebih besar dari nilai 5,991 pada selang kepercayaan 95\%, atau tingkat signifikansi 0,05 dan derajat 
kebebasan 2. Hasil ini menandakan bahwa terdapat perbedaan yang berarti dalam ukuran efek antara kelompok studi menurut jenjang pendidikan. Dari sebaran ukuran efek ada kecendrungan bahwa model PBL lebih efektif jika diterapkan pada jenjang pendidikan yang lebih rendah. Temuan ini didukung oleh meta-analisis sebelumnya yang dilakukan oleh Asror (2016) bahwa ukuran efek penerapan PBL di SMP sebesar 0,94 lebih besar dari ukuran efek penerapan PBL SMA yaitu 0,24. Hasil yang hampir sama juga dilaporkan oleh Suparman et al. (2021) bahwa efek PBL lebih besar ketika di terapkan di SD dari pada di SMP dan SMA. Temuan ini mengejutkan sebab model PBL melibatkan prosedur yang membutuhkan kerja sama, diskusi dan pemecahan masalah. Temuan ini bertentangan dengan anggapan bahwa jenjang pendidikan yang lebih tinggi memiliki kemampuan sensitivitas yang baik. Agar memperoleh konsistensi dalam temuan, diperlukan analisis lebih lanjut terhadap implementasi PBL pada kemampuan matematis dilihat dari aspek jenjang pendidikan.

Terakhir, berdasarkan kombinasi model pembelajaran yang digunakan, ringkasan hasil pada Tabel 7 memperlihatkan nilai statistik Qb yang diperoleh sebagai hasil dari uji homogenitas adalah 7,622 lebih besar dari nilai 3,841 pada selang kepercayaan 95\%, atau tingkat signifikansi 0,05 dan derajat kebebasan 1. Hasil ini menandakan bahwa terdapat perbedaan yang berarti dalam ukuran efek antara kelompok studi menurut kombinasi model pembelajaran yang digunakan. Ada bukti bahwa model PBL lebih efektif jika dikombinasikan dengan penggunaan software pembelajaran matematika. Belum ada studi meta-analisis sebelumnya yang secara khusus menyelidiki karakteristik ini. Temuan ini menandakan bahwa model penerapan PBL dalam pembelajaran matematika sebaiknya dikombinasikan dengan penggunaan media seperti perangkat software pembelajaran.

\section{KESIMPULAN}

Penelitian ini dilakukan untuk mengevaluasi pengaruh PBL terhadap kemampuan pemahaman matematis siswa. Berdasarkan model efek-acak dengan selang kepercayaan 95\% ukuran efek gabungan ditemukan sebesar 0,790 dengan standar eror 0,181. Temuan ini menunjukkan penerapan PBL menghasilkan ukuran efek kemampuan pemahaman matematis siswa yang lebih besar daripada pendekatan konvensional. Standar eror sebesar 0,181 yang cukup tinggi menandakan bahwa ukuran efek tersebut tidak nyata karena adanya variasi dalam ukuran efek tiap studi. Akibatnya pemeriksaan terhadap 
alasan variasi ukuran efek dilakukan yaitu dengan mengevaluasi hubungan karakteristik studi dengan efektivitas PBL. Pertama, berdasarkan tahun studi ditemukan terdapat perbedaan yang berarti dalam ukuran efek antara kelompok studi. Ada kecendrungan bahwa ukuran efek dari kelompok studi yang lebih lama, lebih baik dari kelompok studi yang terbaru. Kedua, terdapat perbedaan yang berarti dalam ukuran efek antara kelompok studi menurut ukuran sampel. Ditemukan bahwa model PBL lebih efektif pada kondisi ukuran sampel diatur 1-30 siswa. Ketiga, terdapat perbedaan yang berarti dalam ukuran efek antara kelompok studi menurut jenjang pendidikan. Ada kecendrungan bahwa model PBL lebih efektif jika diterapkan pada jenjang pendidikan yang lebih rendah. Keempat, terdapat perbedaan yang berarti dalam ukuran efek antara kelompok studi menurut kombinasi model pembelajaran yang digunakan. Ditemukan bahwa model PBL lebih efektif jika dikombinasikan dengan penggunaan software pembelajaran matematika.

Penerapan PBL memberikan efek sedang terhadap kemampuan pemahaman matematis siswa. Akan tetapi, ini hanya didukung oleh studi primer yang dapat dijangkau menggunakan basis data yang telah ditentukan, dan studi primer memuat informasi statistik untuk transformasi ukuran efek. Masih banyak penelitian terkait yang belum dianalisis karena informasi statistik yang dibutuhkan tidak memadai. Penelitian ini belum menjangkau karateristik lain yang mungkin berhubungan dengan efektivitas PBL pada kemampuan matematis siswa misalnya durasi perlakuan, tempat penelitian, materi pembelajaran, dan lain-lain. Akibatnya temuan ini tidak berarti menggambarkan secara keseluruhan efektifitas PBL pada kemampuan matematis siswa. Sebagai saran, peneliti selanjutnya perlu melakukan analisis lebih lanjut terkait efektivitas PBL pada kemampuan matematis siswa dilihat dari berbagai karakteristik studi tersebut dan dengan menganalisis lebih banyak studi sehingga dapat menjangkau variabel yang diperlukan.

\section{UCAPAN TERIMA KASIH}

Kami mengapresiasi Prof. James J Lindsay atas semua bantuan teknis serta kontribusinya untuk penelitian ini.

\section{REFERENCES}

Afridiani, T., Soro, S., \& Faradillah, A. (2020). Pengaruh Model Problem Based Learning (PBL) Berbasis Lembar Kerja Peserta Didik (LKPD) Terhadap Kemampuan $\begin{array}{lllll}\text { Pemahaman Konsep } & \text { Matematis. }\end{array}$ https://doi.org/10.33603/e.v7i1.2532 
Alan, U. F., \& Afriansyah, E. A. (2017). Kemampuan Pemahaman Matematis Siswa Melalui Model Pembelajaran Auditory Intellectualy Repetition Dan Problem Based Learning. Jurnal Pendidikan Matematika, 11(1). https://doi.org/10.22342/jpm.11.1.3890.67-78

Anugraheni, I. (2018). Meta Analisis Model Pembelajaran Problem Based Learning dalam Meningkatkan Keterampilan Berpikir Kritis di Sekolah Dasar. Polygot, 14(1), 9-18. http://dx.doi.org/10.19166/pji.v14i1.789

Aripin, U. (2015). Meningkatkan Kemampuan Pemahaman Matematik Siswa SMP melalui Pendekatan Pembelajaran Berbasis Masalah. P2M STKIP Siliwangi, 2(1), 120. https://doi.org/10.22460/p2m.v2i1p120-127.171

Asror, A. H. (2016). Meta-Analisis: PBL. PRISMA Prosiding Seminar Nasional Matematika, 508-513.

Borenstein, M., \& Hedges, L. V. (2009). Introduction to Meta-Analysis (first). WILEY A John Wiley and Sons, Ltd, Publication. https://onlinelibrary.wiley.com/doi/book/10.1002/9780470743386

Borenstein, M., Hedges, L. V, \& Rothstein, H. R. (2009). Introductionto Meta-Analysis (Issue January). John Wiley \& Sons.

Ceker, E., \& Ozdamli, F. (2016). Features and characteristics of problem based learning. Cypriot Journal of Educational Sciences, 11(4), 195-202. www.cjes.eu

Coe, R. (2002). It 's the Effect Size, Stupid. In Educational Research (Issue September, pp. 1-18).

Cohen, L., Manion, L., \& Morrison, K. (2007). Research Methods in Education (7th ed.). Routledge.

Dalim, D., Rosita, C. D., \& Dewi, I. L. K. (2019). Pembelajaran Model Problem Based Learning Terhadap Kemampuan Pemahaman Konsep Matematis Siswa. Snpm, 1(1), $166-173$.

Demirel, M., \& Dağyar, M. (2016). Effects of Problem-Based Learning on Attitude: A Meta-analysis Stud. EURASIA Journal of Mathematics, Science \& Technology Education, 12(8), 2115-2137. https://doi.org/10.12973/eurasia.2016.1293a

Dewimarni, S. (2017). Analisis Kemampuan Komunikasi Dan Pemahaman Konsep Aljabar Linier Pada Mahasiswa Universitas Putra Indonesia 'YPTK' Padang. AlJabar: Jurnal Pendidikan Matematika, 8(1), 53-62.

Dochy, F., Segers, M., Van den Bossche, P., \& Gijbels, D. (2003). Effects of problembased learning: A meta-analysis. Learning and Instruction, 13(5), 533-568. https://doi.org/10.1016/S0959-4752(02)00025-7

Franzen, M. (2020). Meta-analysis. In H. V. Zeigler \& T. . Shackelford (Eds.), Encyclopedia of Personality and Individual Differences (p. 5925). Springer, Cham. https://doi.org/10.1007/978-3-319-24612-3_1326

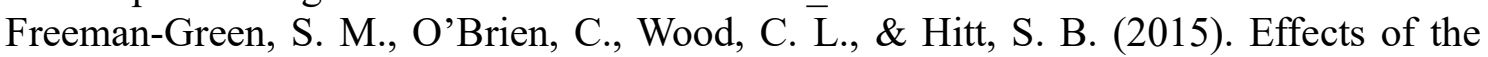
SOLVE strategy on the mathematical problem solving skills of secondary students with learning disabilities. Learning Disabilities Research and Practice, 30(2), 7690. https://doi.org/10.1111/ldrp.12054

Gijbels, D., Dochy, F., Van Den Bossche, P., \& Segers, M. (2005). Effects of problembased learning: A meta-analysis from the angle of assessment. Review of Educational Research, 75(1), 27-61. https://doi.org/10.3102/00346543075001027

Glass, G. V. (2015). Meta-analysis at middle age: A personal history. Research Synthesis Methods, 6(3), 221-231. https://doi.org/10.1002/jrsm.1133

Green, S. (2005). Systematic Reviews and Meta-Analysis. Evidence-Based Medicine And 
Healthcare, 46(6), 270-24. https://doi.org/10.1002/9781444345100.ch5

Haidich, A. B. (2010). Meta-analysis in Medical Research. Hippokratia, 14(Supp 1), 29 37. https://pubmed.ncbi.nlm.nih.gov/21487488/

Hasibuan, A. M., Saragih, S., \& Amry, Z. (2019). Development of Learning Materials Based on Realistic Mathematics Education to Improve Problem Solving Ability and Student Learning Independence. International Electronic Journal of Mathematics Education, 14(1), 243-252. https://doi.org/10.29333/iejme/4000

Hidayat, R., \& Nurrohmah. (2016). Analisis Peningkatan Kemampuan Pemahaman Konsep Matematis Siswa Mts Lewat Penerapan Model Pembelajaran Problem Based Learning Berbantuan Software Geogebra Berdasarkan Kemampuan Awal Matematika. Jppm, 9(1).

Higgins, S., \& Katsipataki, M. (2015). Evidence from meta-analysis about parental involvement in education which supports their children's learning. Journal of Children's Services, 10(3), 280-290. https://doi.org/10.1108/JCS-02-2015-0009

Jacinto, H., \& Carreira, S. (2017). Mathematical Problem Solving with Technology: the Techno-Mathematical Fluency of a Student-with-GeoGebra. International Journal of Science and Mathematics Education, 15(6), 1115-1136. https://doi.org/10.1007/s10763-016-9728-8

Juandi, D., Kusumah, Y. S., Tamur, M., Perbowo, K. S., Siagian, M. D., Sulastri, R., \& Negara, H. R. P. (2021). The Effectiveness of Dynamic Geometry Software Applications in Learning Mathematics: A Meta- Analysis Study. International Journal Interactive Mobile Technologies, 15(02), 18-37. https://doi.org/10.3991/ijim.v15i02.18853

Ke, F., \& Clark, K. M. (2020). Game-Based Multimodal Representations and Mathematical Problem Solving. International Journal of Science and Mathematics Education, 18(1), 103-122. https://doi.org/10.1007/s10763-018-9938-3

Khan, S. (2020). Meta-Analysis. In S. Khan (Ed.), Meta-Analysis (First). Springer Nature Singapore Pte Ltd. https://doi.org/10.1007/978-981-15-5032-4

Kusmaryono, I. (2014). The importance of mathematical power in mathematics learning. International Conference on Mathematics, Sciense, and Education, May, 35-40.

Lambertus. (2016). Developing skills understanding of mathematical. International Journal of Education and Research, 4(7), 315-326. https://www.ijern.com/journa1/2016/July-2016/25.pdf

Marlena, L., \& Nugraheni, E. A. (2019). Probit Regression Analysis in Estimating the Effect of Learning Assisted by Cabri 3D on Students' Mathematical Understanding Ability. Al-Jabar: Jurnal Pendidikan Matematika, 10(2), 319-326. https://doi.org/10.24042/ajpm.v10i2.4729

Minarni, A., Napitupulu, E. E., \& Husein, R. (2016). Mathematical understanding and representation ability of public junior high school in North Sumatra. Journal on Mathematics Education, 7(1), 43-56. https://doi.org/10.22342/jme.7.1.2816.43-56

Muhsin, \& Taufiq. (2019). Pembelajaran Berbasis Masalah Untuk Meningkatkan Kemampuan Pemahaman Matematis Siswa. Journal of Didactic Mathematics, 1(1), 542-553. https://doi.org/10.34007/jdm.v1i1.148

Mullen, B., Muellerleile, P., \& Bryant, B. (2001). Cumulative meta-analysis: A consideration of indicators of sufficiency and stability. Personality and Social Psychology Bulletin, 27(11), 1450-1462. https://doi.org/10.1177/01461672012711006

Munawaroh, L., \& Deniyanti Sampoerno, P. (2018). Pengaruh Problem Based Learning 
Terhadap Kemampuan Penalaran Matematis Dan Kemampuan Pemahaman Konsep Matematika Ditinjau Dari Kemampuan Awal Matematika. Prosiding Seminar Dan Diskusi Nasional Pendidikan Dasar.

NCTM. (2000). Principles for School Mathematics. Reston: National Council of Teacher of Mathematics. https://www.nctm.org/uploadedFiles/Standards_and_Positions/PSSM_ExecutiveSu mmary.pdf

Paloloang, M. F. B., Juandi, D., Tamur, M., Paloloang, B., \& Adem, A. M. G. (2020). Meta analisis: pengaruh problem-based learning terhadap kemampuan literasi matematis siswa di indonesia tujuh tahun terakhir. Aksioma: Jurnal Program Studi Pendidikan Matematika, 9(4), 851-864. https://doi.org/10.24127/ajpm.v9i4.3049

Pigott, T. D. (2012). Advances in Meta-Analysis. In Statistics for Social and Behavioral Sciences. Springer New York Dordrecht Heidelberg London. https://doi.org/10.1007/978-1-4614-2278-5

Prahmana, R. C. I. (2013). Designing Division Operation Learning In The Mathematics. The First South East Asia Design/Development Research (SEA-DR), April 2013, 391-398.

Qin, Y., Wang, Y., \& Floden, R. E. (2016). The Effect of Problem-Based Learning on Improvement of the Medical Educational Environment: A Systematic Review and Meta-Analysis. Medical Principles and Practice, 25(6), 525-532. https://doi.org/10.1159/000449036

Rahmadani, H., \& Acesta, A. (2017). Pengaruh Penerapan Model Pembelajaran Problem Based Learning Terhadap Pemahaman Konsep Siswa. Jurnal Sekolah Dasar, 2(1), 9. https://doi.org/10.1017/CBO9781107415324.004

Rosli, R., Capraro, M. M., \& Capraro, R. M. (2014). The effects of problem posing on student mathematical learning: A meta-analysis. International Education Studies, 7(13), 227-241. https://doi.org/10.5539/ies.v7n13p227

Sari, W. P., Harman, H., \& Aisyah, A. (2019). Perbandingan Kemampuan Pemahaman Konsep Matematis Siswa Dengan Model Pembelajaran Inquiry Learning Dan Model Pembelajaran Problem Based Learning Pada Siswa Kelas Vii Smpn 5 Kota Jambi. PHI: Jurnal Pendidikan Matematika, 3(1), 46. https://doi.org/10.33087/phi.v3i1.64

Schmidt, F. L., \& Hunter, J. E. (2015). Methods of Meta-Analysis: Correcting Error and Bias in Research Findings (Third). 55 City Road, London: SAGE Publications, Ltd. https://doi.org/10.4135/9781483398105

Siddaway, A. P., Wood, A. M., \& Hedges, L. V. (2019). How to Do a Systematic Review: A Best Practice Guide for Conducting and Reporting Narrative Reviews, MetaAnalyses, and Meta-Syntheses. Annual Review of Psychology, 70(1), 747-770. https://doi.org/10.1146/annurev-psych-010418-102803

Siregar, N., Armanto, D., \& Saragih, S. (2011). Penerapan Pembelajaran Berbasis Masalah Untuk Meningkatkan Pemahaman Konsep Dan Pengetahuan Prosedural Matematika Siswa Smp. Jurnal Pendidikan Matematika, 5(2), 137-150.

Stanley, T. D., Doucouliagos, H., Giles, M., Heckemeyer, J. H., Johnston, R. J., Laroche, P., Nelson, J. P., Paldam, M., Poot, J., Pugh, G., Rosenberger, R. S., \& Rost, K. (2013). Meta-analysis of economics research reporting guidelines. Journal of Economic Surveys, 27(2), 390-394. https://doi.org/10.1111/joes.12008

Suparman, Juandi, D., \& Tamur, M. (2021). Review of problem-based learning trends in 2010-2020: A meta-analysis study of the effect of problem-based learning in enhancing mathematical problem-solving skills of Indonesian students. Journal of 
Physics: Conference Series, 1772(1), 012103. https://doi.org/10.1088/17426596/1722/1/012103

Supriatna, R., \& Afriansyah, E. A. (2017). Kemampuan Pemahaman Matematis Peserta Didik Melalui Cooperative Learning Tipe Pair Checks Vs Problem Based Learning. Jurnal Ilmu Pendidikan Fisika, 3(1), 1-6. https://doi.org/10.1016/j.profnurs.2007.01.018

Susanti, N., Juandi, D., \& Tamur, M. (2020). The Effect of Problem-Based Learning (PBL) Model On Mathematical Communication Skills of Junior High School Students - A Meta-Analysis Study. JTAM (Jurnal Teori Dan Aplikasi Matematika), 4(2), 145-154. https://doi.org/10.31764/jtam.v4i2.2481

Tamur, M, Jehadus, E., Nendi, F., Mandur, K., \& Murni, V. (2020). Assessing the effectiveness of the contextual teaching and learning model on students mathematical understanding ability: a meta-analysis study. Journal of Physics: Conference Series, 1657(1), 012067. https://doi.org/10.1088/1742$6596 / 1657 / 1 / 012067$

Tamur, M, \& Juandi, D. (2020). Effectiveness of Constructivism Based Learning Models Against Students Mathematical Creative Thinking Abilities in Indonesia: A MetaAnalysis Study. Pervasive Health: Pervasive Computing Technologies for Healthcare, 1, 107-114. https://doi.org/10.4108/eai.12-10-2019.2296507

Tamur, Maximus, Jehadus, E., Negara, H. R. P., Siagian, M. D., Marzuki, M., \& Sulastri, R. (2021). Pembelajaran Selama Krisis COVID - 19: Meta - Analisis dari Sudut Hasil Belajar yang Diukur. Jurnal Riset Teknologi Dan Inovasi Pendidikan (JARTIKA), 4(1), 101-108. https://doi.org/10.36765/jartika.v4i1.413

Tamur, Maximus, Juandi, D., \& Adem, A. M. G. (2020). Realistic Mathematics Education in Indonesia and Recommendations for Future Implementation: A Meta-Analysis Study. Jurnal Teori Dan Aplikasi Matematika, 4(1), 17-27. https://doi.org/10.31764/jtam.v4i1.1786

Tamur, Maximus, Juandi, D., \& Kusumah, Y. S. (2020). The Effectiveness of the Application of Mathematical Software in Indonesia: A Meta-Analysis Study. International Journal of Instruction, 13(4), 867-884. https://doi.org/10.29333/iji.2020.13453a

Turgut, S., \& Turgut, I. G. (2018). The Effects of Cooperative Learning on Mathematics Achievement in Turkey: A Meta-Analysis Study. International Journal of Instruction, 11(3), 663-680. https://doi.org/10.12973/iji.2018.11345a

Wang, J., Xu, Y., Liu, X., Xiong, W., Xie, J., \& Zhao, J. (2016). Assessing the effectiveness of problem-based learning in physical diagnostics education in China: A meta-analysis. Scientific Reports, 6(May), 1-7. https://doi.org/10.1038/srep36279

Wardhani, R. A., Coesamin, M., \& Caswita. (2016). Efektivitas Problem Based Learning Ditinjau Dari Pemahaman Konsep Matematis Siswa. Jurnal Pendidikan Matematika Universitas Lampung, 4(1), 1-8.

Warniasih, K. (2018). Efektivitas Model Problem Based Learning Ditinjau Dari Pemahaman Konsep Matematika Siswa Kelas Vii Sekolah Menengah Pertama. AKSIOMA: Jurnal Matematika Dan Pendidikan Matematika, 9(2), 92. https://doi.org/10.26877/aks.v9i2.2911

White, I. R. (2015). Network meta-analysis. The Stata Journal, 4, 951-985. https://doi.org/10.1177/1536867X1501500403

Yanto, F., Festiyed, F., Iswri, M., \& Enjoni, E. (2019). Meta-Analysis: Improving Creativity through Assessment in a Problem-Based Learning Environment. 
Journal of Honai Math, Vol. 4, No. 1, pp. 1-18, April 2021

Sari, Juandi, Tamur, \& Adem, Meta-Analysis: Mengevaluasi Efektivitas Problem-based Learning ...

178(ICoIE 2018), 23-26. https://doi.org/10.2991/icoie-18.2019.6

Yunita, Juandi, D., Tamur, M., Adem, A. M. G., \& Pereira, J. (2020). A meta-analysis of the effects of problem-based learning on students 'creative thinking in mathematics. Beta: Jurnal Tadris Matematika, 13(2), 104-116. https://doi.org/10.20414/betajtm.v13i2.380 